\title{
Aspectos identitários na titulação do jornal Tais Timor *
}

Regina Helena Pires de Brito**

Colónia portuguesa desde o século XVI, Timor-Leste esteve ocupado pelo Japão durante três anos, na época da Segunda Guerra Mundial, e foi invadido pela Indonésia em Dezembro de 1975, num domínio que se arrastou até 1999. Ao longo desses quase vinte e cinco anos, vítimas de dura repressão (como tortura e assassinatos) e exploração (trabalho escravo e semi-escravo), cerca de 300 mil timorenses - de uma população de 800 mil habitantes - foram mortos.

Apesar de a língua portuguesa ter chegado ao território no século XVI e de se ter tornado uma das línguas mais faladas da ilha, até 1950 os eventuais leitores de textos em português eram apenas religiosos católicos e alguns funcionários da administração colonial - o que não representava grande estímulo para o desenvolvimento da imprensa no território. Quando os japoneses o deixaram, depois da Segunda Guerra, os portugueses retornaram a Timor-Leste com a intenção (fracassada) de "reconstruir o país em termos culturais"1. Contudo, os portugueses que para lá seguiram eram basicamente militares e funcionários administrativos: não havia nem docentes, nem intelectuais que ajudassem a fomentar atividades académico-culturais. Para se ter uma ideia, nessa época, o ensino era feito por "agentes de ensino" num único liceu, para uma população estudantil de apenas $25 \%$ da população total. A despeito disso, antes do 25 de Abril e da invasão indonésia, circulavam em Timor algumas publicações periódicas, como a revista Seara (da diocese de Díli); a Província de Timor, um jornal do exército em Timor; e $A$ Voz de Timor, jornal patrocinado pelo governo provincial, dirigido por Lopes da Cruz (ex-seminarista e membro da ANP - Associação Nacional Popular - partido caetanista e o único autorizado por lei).

Imediatamente após o 25 de Abril, A Voz de Timor teve lampejos de se tornar uma publicação diferenciada, desvinculada da oficialidade, com mais páginas e maior tira-

\footnotetext{
* Este artigo corresponde à comunicação oral "Voz e identidade na titulação de jornais timorenses", apresentada no I Congresso Luso-Brasileiro de Estudos Jornalísticos (9 a 12 de Abril de 2003 - Universidade Fernando Pessoa, Porto, Portugal). Sendo a autora brasileira, neste texto é usada a ortografia correspondente ao português do Brasil.

** Docente do Programa de Pós-Graduação em Letras da Universidade Presbiteriana Mackenzie de São Paulo. Pós-Doutoranda no Instituto de Ciências Sociais da Universidade do Minho, sob a supervisão do Prof. Dr. Moisés de Lemos Martins. ${ }^{1}$ Ver "A imprensa em Timor antes do 25 de Abril", de Paulo Pires. (http://www.instituto-camoes.pt/revistal4n.htm página acedida em 17/03/2003)
} 
gem. No entanto, a luta fratricida entre a Fretilin (Frente Revolucionária do Timor-Leste Independente) e a Apodeti (Associação Popular Democrática Timorense) e a invasão indonésa interromperam qualquer possibilidade do desenvolvimento de actividades de imprensa em língua portuguesa na ilha.

Como parte da estratégia da política de "destimorização", os invasores indonésios forçaram o ensino de sua língua, a bahasa indonésia (variante do malaio), desestimularam o emprego da língua nacional, o tétum ${ }^{2}$, e proibiram o uso da língua portuguesa. A imprensa local, naturalmente, foi sufocada e as já escassas publicações (sempre em português) que circulavam no território foram interrompidas pelo governo de Jacarta.

Nesse contexto, falar português poderia significar a morte. Durante duas décadas e meia, com reduzidas oportunidades para empregar a fala, a leitura e a escrita da língua portuguesa, o povo de Timor resistiu em defesa de seu território e de sua liberdade. Hoje, com a sua adopção como língua oficial ao lado do tétum, o português assume o sentido de perspectiva de um futuro menos sangrento:

"Foi a língua portuguesa que os nossos dirigentes usaram para contactar um ao outro, no interior e no exterior; isto é, nos países amigos da língua oficial portuguesa para convocar a SOLIDARIEDADE. Por isso, não há razão nenhuma de rejeitar a adopção da língua portuguesa como nossa língua oficial porque não estamos a andar sozinhos."

(Texto-depoimento de timorense do distrito de Cova Lima - Junho/2001)

“A língua portuguesa vai ser língua oficial e é como um caminho que liga os países que falam português, nas relações diplomáticas e negócios. A língua portuguesa desenvolve Timor e contribui [para] o desenvolvimento e o progresso e para combater a ignorância e a pobreza."

(Texto-depoimento de timorense do distrito de Liquiçá - Agosto/2001)

Pensamento corroborado pelo Presidente Xanana Gusmão, durante a IV Conferência de Chefes de Estado e de Governo da CPLP (Brasília/Brasil), quando TimorLeste passou a figurar como membro efetivo da CPLP:

"A opção política de natureza estratégica que Timor-Leste concretizou com a consagração constitucional do Português como língua oficial a par com a língua nacional, o tétum, reflecte a afirmação da nossa identidade pela diferença que se impôs ao mundo e, em particular, na nossa região onde, deve-se dizer, existem também similares e vínculos de carácter étnico e cultural, com os vizi-

\footnotetext{
${ }^{2}$ Além do tétum (língua de integração nacional), em Timor-Leste há cerca de duas dezenas de outras línguas originais, pertencentes à família das línguas austronésias ou à família das línguas papuas, diversidade linguística que se explica principalmente por Timor ter sido parte de rotas de migrações várias e que caracteriza o multilinguismo local. De modo geral, antes da invasão indonésia, em 1975, a situação linguística do território apresentava-se em três níveis: (1) línguas locais - veículos de comunicação nas diversas localidades, como o bunak, o kemak, o galole, o fataluko etc.; (2) língua veicular e integradora - o tétum; (3) língua administrativa - o português - única língua normalmente escrita e que também exercia uma função integradora, pelo menos na camada dirigente e no parco ambiente letrado.
} 
nhos mais próximos. Manter esta identidade é vital para consolidar a soberania nacional." 3

Em Maio de 1999, instalou-se no território a Missão de Assistência das Nações Unidas a Timor-Leste (UNAMET) e em 30 de Agosto realizou-se um plebiscito junto da população, que votou maioritariamente a favor da independência. As milícias pró-anexação à Indonésia, inconformadas com o resultado da consulta popular, executaram timorenses, incendiaram casas, perseguiram e mataram funcionários do órgão de representação da ONU no território. Assim, entraram em acção as forças multinacionais da ONU para restabelecer a paz, tendo sido instituída uma administração transitória (UNTAET - Administração Transitória das Nações Unidas em Timor-Leste), chefiada pelo brasileiro Sérgio Vieira de Mello, a fim de viabilizar uma agenda segura de independência e de reconstrução do país. Despontam figuras engajadas na reconstrução da identidade timorense, como Xanana Gusmão, Padre Filomeno Jacob, Bispo Carlos Ximenes Belo e José Ramos-Horta (ambos Nobel da Paz em 1996).

Logo de início, a Administração Transitória ${ }^{4}$ passa a produzir e distribuir, gratuitamente, "uma fonte de informação bimensal publicada em tétum, inglês, português e bahasa indonésia" - o Tais Timor ${ }^{5}$. O nome do jornal é extremamente significativo no contexto timorense, já que o tais é um tecido tradicional, peça principal do artesanato local, usado em ocasiões especiais, símbolo de extremo respeito.

O jornal, produzido em Darwin (Austrália), numa tiragem de 75000 exemplares $^{6}$ e que circulou de 14 de Fevereiro de 2000 a Maio de 2002, autodefine-se como "um serviço público de informação (...) escrito, editado e desenhado pelo Gabinete de Comunicação e Informação Pública".

Originalmente redigido em inglês, língua de trabalho da ONU, o Tais Timor era depois traduzido para os outros três idiomas. Isto explica que se encontrem na edição em língua portuguesa construções sintácticas estranhas à estrutura do português padrão, emprego vocabular inadequado, distorções ortográficas, diferenças na pontuação - observe-se, por exemplo, o texto do expediente:

"O nome Tais Timor conjura a image do cuidadoso e laboroso processo envolvido na tecelagem do tecido tradicional Timorense (...) Os diferentes 'ingredientes' que constituem Timor-Leste unem-se durante o tempo de transição para a recontrução do país (...)”. (Itálicos nossos).

\footnotetext{
${ }^{3}$ Alocução do Presidente Xanana Gusmão na íntegra em www.cplp.org/noticias/ccegc/di7.htm [página acedida em 03/ 08/2002].

${ }^{4}$ Destaque-se que durante a Administração Transitória surgiram alguns meios de comunicação social: duas estações de rádio (Rádio Falintil/Voz da Esperança - Díli - e Rádio Timor Kmanek, da diocese de Díli com transmissão para alguns pontos do território) e quatro publicações impressas (nenhuma delas em português): Lalenok (revista semanal, vendida em Díli), Timor Post (circulando apenas em Díli, jornal de quatro páginas, publicado duas vezes por semana), Lian Maubere (semanário publicado pela OnG Fordem) e Talit @kun (jornal quinzenal).

${ }^{5}$ Em http://www.onuportugal.pt/tais_timor_-_timor_leste.html estão disponíveis quase todos os números do Tais Timor. ${ }^{6}$ Quantidade relevante, considerando-se a população actual de 800 mil habitantes.
} 
O projecto gráfico é simples: o cabeçalho em que se lê TAIS TIMOR em grossos tipos na cor preta, é limitado por um fio superior de 12 pontos e por um fio inferior de 3 pontos (na cor azul que identifica a ONU), mantém-se até à edição número 19 (Novembro de 2000). A partir desse número, muda-se o tipo de letra, e passa-se a escrever em caixa alta e baixa. Além disso, a cada edição, a palavra Timor aparecerá numa cor diferente, enquanto a palavra Tais aparecerá sempre na cor preta, num jogo cromático instaurado no nome do jornal e que nos pode remeter ao período de obscuridade vivido em Timor que hoje se quer "colorido", "renovado", "recomposto, "reconstruído" - como o tais, que, agora, se neutraliza para que o país seja tecido novamente, simbolizando o país a caminho da consolidação como nação independente.

No conjunto do periódico, destaca-se uma "coluna" que se manterá em todas as edições: “Tiu responde a perguntas”. É o espaço em que uma voz assumida por um fictício timorense, o "Tiu” (tio), se dirige direta e intimamente ao público: "Olá caro leitor. Acredite ou não. Timor-Leste tem seu próprio jornal, Tais Timor, para falar das mudanças interessantes que estão a acontecer no nosso país”. Essa voz que, de forma dialogada, responde a eventuais questões de populares, procura tanto dar um carácter de verdade e confiabilidade às informações do Tais Timor ("as notícias neste jornal são extremamente rigorosas porque nós obtemos as nossas respostas sobre a UNTAET directamente dos funcionários da ONU"), quanto legitimar a existência do jornal e a presença da ONU no país ("Talvez seja importante partilhar este meio de comunicação com os seus amigos, familiares e especialmente com os que regressam a Timor-Leste”). Por fim, cabe destacar o emprego constante das funções conativa e emotiva nesta coluna, que destoa do teor predominantemente referencial e metalinguístico do restante da publicação. Não é por acaso que a coluna serve para esse contacto mais imediato com o interlocutor, visto que no jornalismo moderno são exatamente os cronistas e colunistas que se distanciam das ortodoxias do discurso mediático, compondo textos com maior subjectividade e proximidade com o leitor.

A edição de Junho de 2001 (n. 27) destaca, na primeira página, uma "Nota Editorial sobre o Tais Timor Mensal”, anunciando novos rumos na publicação:

“As coisas mudam, geralmente para melhor. Nas próximas edições do Tais Timor irão testemunhar a transformação do Tais Timor numa publicação que reflectirá as tendências e realidades actuais em Timor-Leste, enfatizando alterações que vão desde a periodicidade (agora mensal) até a explicitação de que Tais Timor, na verdade, não é um jornal, mas sim uma publicação que regista as iniciativas mais importantes da UNTAET/ATTL, embora cumprisse, até o momento, o papel de preencher o vazio criado pela destruição imposta à indústria local de comunicação social”.

A Nota encerra assinalando o distanciamento desse enunciador com relação ao cidadão timorense, explicitado pelo uso do pronome possessivo de 2. ${ }^{a}$ pessoa: “A Unidade de Publicações espera que considerem as novas mudanças encorajadoras e mais adequadas às vossas próprias necessidades informativas.” 
Nas primeiras edições, todo o texto vinha impresso a preto; mas, a partir do número 7 (Maio/2000), alguns títulos começaram a aparecer em azul. A edição número 14 (Setembro/2000) comemora o primeiro aniversário do governo de transição no país e assinala, também, um novo Tais Timor: com fotos coloridas e títulos em cores diversas. O número de páginas da publicação oscilou: até o número 13, compunha-se com apenas quatro páginas; a edição especial de aniversário (n. $\left.{ }^{\circ} 14\right)$ aparece com 12 ; passando a oito nas edições seguintes até ao número 24; da edição 25 até à 35, manteve 12 páginas; a última edição terá 20 páginas.

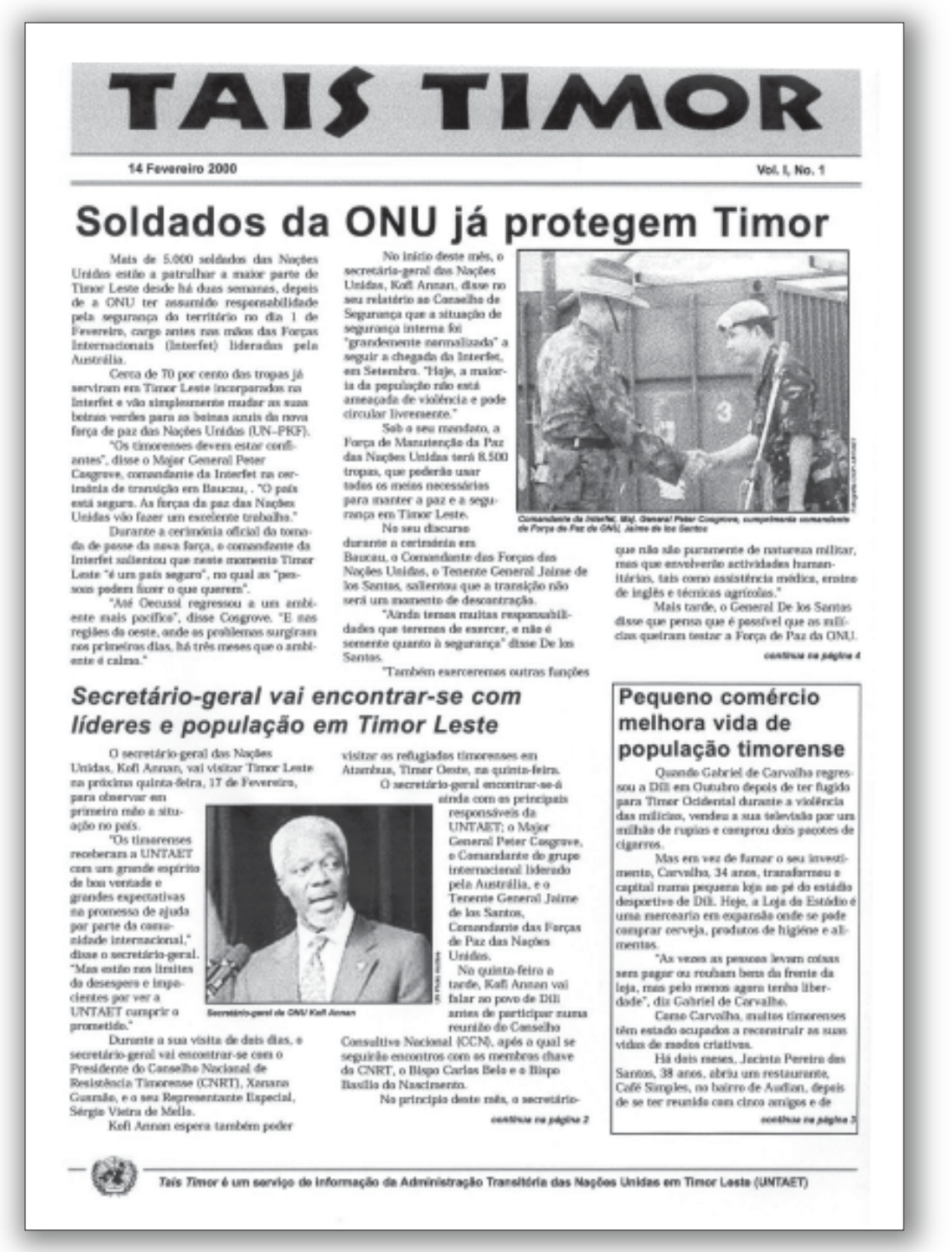


Na segunda página da primeira edição, há uma espécie de editorial intitulado "Uma nova voz em Timor-Leste", apresentando a publicação como dirigida aos esforços de reconstrução e à preparação do país para a independência. O compromisso do jornal é o de veicular notícias a respeito das actividades da UNTAET e o de possibilitar que a comunidade afixe suas próprias notícias ao lado das da UNTAET - assim, a publicação apresenta-se com uma voz individualizada, diferenciada da voz da população. Mais adiante, acentua a importância do estabelecimento de órgãos de comunicação social independentes em Timor-Leste e arremata:

“Temos trabalhado para apoiar vários grupos timorenses que querem lançar os seus órgãos de comunicação.

Felizmente, a UNTAET não está sozinha. Além da motivação e da determinação dos timorenses, há o compromisso e o apoio de governos doadores, fundações e Organizações Não-Governamentais".

Por fim, num discurso sensibilizador, apresenta o nome da publicação ao leitor timorense:

"Uma última palavra sobre o nosso título. Tais Timor foi escolhido porque nos faz lembrar o longo, cuidadoso e detalhado processo que inclui muitos dos ingredientes essenciais para se tecer os tais, os panos tradicionais usados para todos os acontecimentos importantes da vida timorense.

Timor-Leste também é formado por muitos “ingredientes”. Quando as casas forem construídas, os campos derem colheitas, as pessoas abrirem negócios e as instituições forem estabelecidas, Timor-Leste, tal como o tais, terá sido tecido como uma nova nação".

Esta nota da redação, será repetida, a partir do número 2, edição após edição, sempre como informação final do jornal.

O discurso do jornal pauta-se na referencialidade, na impessoalidade e no distanciamento da voz que ali fala: trata-se de um veículo de informação oficial da ONU , cujo intuito é o de realçar o trabalho das forças de paz das Nações Unidas em Timor-Leste.

Passemos a focalizar a titulação da primeira página desse periódico. Sendo o título um discurso pautado na interactividade, é ele o responsável pelo contato inicial do leitor com a notícia, cabendo-lhe o papel de identificar, anunciar, sintetizar uma determinada informação, funcionando como um isco, iman e instrumento específico para persuadir à leitura e provocar a curiosidade ${ }^{7}$.

Enquanto os jornais de cunho comercial utilizam titulações que procuram captar a atenção do leitor, no sentido de seduzi-lo a "adquirir" a notícia, o Tais Timor, distribuído gratuitamente, apresenta títulos que, na maior parte das vezes, funcionam como dispositivos informativos. No entanto, apesar de não haver a preocupação mercadológica com a vendagem ou com o retorno comercial do veículo, é necessário que a credibilidade da voz que ali se apresenta também se estabeleça junto ao público. É preciso que a

${ }^{7}$ Nunes, M. R. (1983). O Estilo na Comunicação. Rio de Janeiro: Agir, p. 69. 
notícia publicada cative o leitor e consiga reproduzir-se em outras vozes, repercuta junto a outras pessoas e ainda junto do grande número de analfabetos do território. Daí que o Tais Timor também não se furte a usar titulações com forte presença da função emotiva, de modo a causar impacto emocional no leitor (por meio de imagens afectivas, como o uso de exclamações e verbos no imperativo) e de modo a seduzi-lo a ler o conteúdo da matéria (por meio de imagens semelhantes às empregadas pela imprensa comercial e sobretudo pelo discurso publicitário). Como exemplo, apresentamos a edição comemorativa de um ano da entrada das forças de paz em Timor-Leste. Nela, observa-se a manchete altamente subjectiva que instaura um jogo de sentido construído com a exclamação “Que ano!” conjugada com a foto de Xanana Gusmão, na qual se vê o povo estendendo a mão para o seu líder, que mantém a mão direita erguida, num plano mais alto do que o das pessoas que se lhe dirigem:

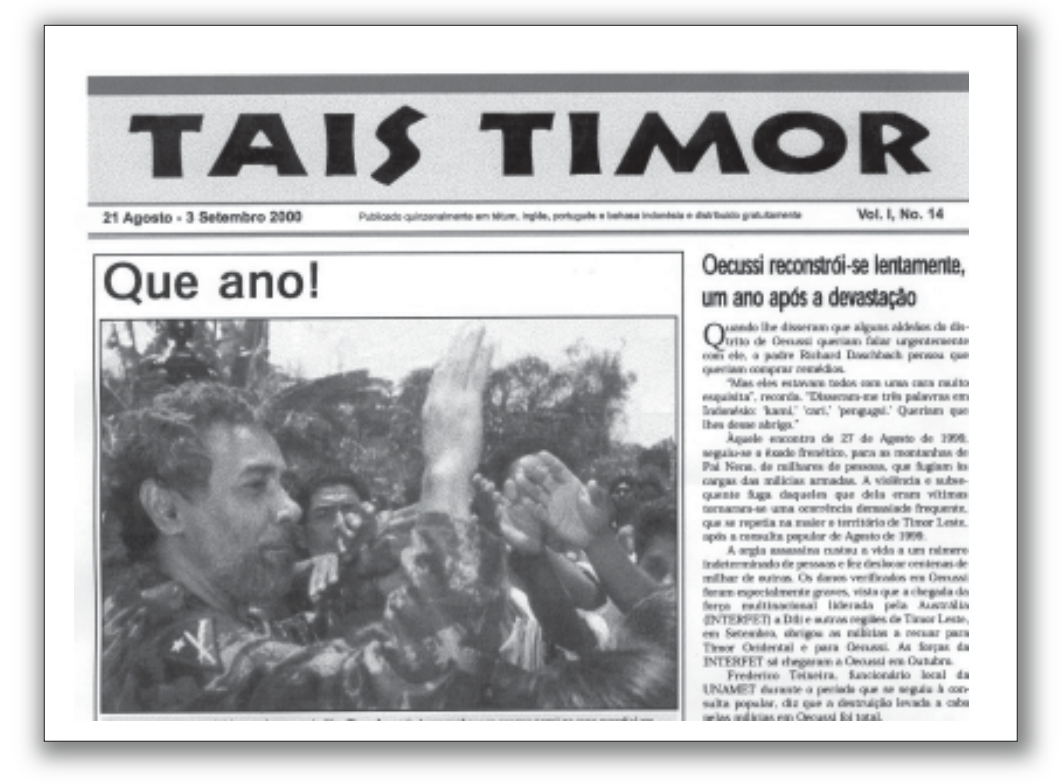

$\mathrm{Na}$ maior parte das edições, diferentemente do que ocorre em jornais em que a notícia é a mercadoria, e que, portanto, espera da titulação que capte a atenção do leitor de tal modo que o motive à compra do jornal, os títulos do Tais Timor (distribuído gratuitamente) funcionam como dispositivos informativos: o importante não reside na vendagem do jornal, mas sim no estabelecimento da credibilidade da voz e do discurso que ali se apresenta.

Essa voz, de um sujeito para além do texto, ou ethos, confere autoridade e possibilita ao leitor a construção de uma representação do enunciador, que passa a exercer o papel de "fiador" do dito. Este "fiador", por sua vez, constrói-se a partir de vários indícios textuais, de representações sociais e de estereótipos culturais (ou seja, o leitor 
confere a esse fiador um carácter e uma corporalidade) ${ }^{8}$. O leitor (denominado coenunciador, graças à ideia de interactividade constitutiva ${ }^{9}$ ) não é apenas alguém para quem são apresentadas ideias ou factos, mas também é aquele que tem acesso ao dito por meio de uma "maneira de dizer" que remete a uma "maneira de ser":

"O texto não se destina a ser contemplado, configurando-se como enunciação dirigida a um co-enunciador que é preciso mobilizar, fazê-lo aderir 'fisicamente' a um determinado universo de sentido. O poder de persuasão de um discurso consiste em parte em levar o leitor a se identificar com a movimentação de um corpo investido de valores socialmente especificados. A qualidade do ethos remete, com efeito, à imagem deste 'fiador' que, por meio de sua fala, confere a si próprio uma identidade compatível com o mundo que deverá construir em seu enunciado. ${ }^{10}$

No Tais Timor, emerge uma voz que estabelece uma identidade ao assumir uma "maneira de dizer" (que se pretende objectiva, referencial, informativa, denotativa), que exterioriza a sua "maneira de ser", corporificada num caleidoscópio humano (soldados dirigentes, administradores, advogados, médicos, professores, etc., de diferentes nacionalidades) metonimizado pela ONU.

Observar alguns títulos (extraídos das primeiras páginas) pode revelar essa voz:

- A ONU que resguarda: Soldados da ONU já protegem Timor (n. ${ }^{\circ} 1,14 / 02 / 2000$ )

- A ONU que agiliza a reconstrução: Projectos financiados pela ONU têm rápido impacto como objectivo (n. $\left.{ }^{\circ} 2,28 / 02 / 2000\right)$

- A ONU que disciplina: A UNTAET anuncia política de "tolerância zero" em relação a indivíduos armados (n. ${ }^{\circ}$ 7, 15/05/2000)

- A ONU que reestrutura: UNTAET-Timor-Leste dá forma a novo governo e órgão legislativo (n. $\left.{ }^{\circ} 12,24 / 07 / 2000\right)$

- A ONU que oferece o emprego: A função pública põe os timorenses a trabalhar (n. $\left.{ }^{\circ} 25,26 / 03 / 2001\right)$

- A ONU que acolhe: A Força de Manutenção de Paz preparada para os Refugiados que Regressam (n. $\left.{ }^{\circ} 26,05 / 2001\right)$

- A ONU que orienta: Campanha de conversão ao dólar vai de vento em popa (n. ${ }^{\circ}$ 27, 06/2001)

Esse ethos parece criar, na singularidade da sigla da organização, uma múltipla identidade que se camufla e ao mesmo tempo se desvenda aos olhos do timorense: a presença das Nações Unidas - nas diversas actividades - era relativamente sentida nas

\footnotetext{
${ }^{8}$ Cf. Maingueneau, D. (1997). Novas Tendências em Análise do Discurso. São Paulo: Pontes, Campinas: Editora da Universidade de Campinas, pp. 44-6.

${ }^{9}$ Maingueneau, D. (2001). Análise de textos de comunicação. São Paulo: Cortez.

${ }^{10}$ Idem.
} 
ruas da capital, nas aldeias e nas montanhas, e fortemente vivida nos gabinetes dos edifícios reconstruídos e nos saudáveis salários recebidos. Tais Timor, como veículo oficial, era a voz instituída e que legitimava as iniciativas da Administração Transitória no território. Servindo ou não a interesses de um discurso de autoridade, a circulação desta publicação possibilitou aos timorenses o reencontro com a sua voz silenciada, com a sua palavra interdita.

Como informação complementar, assinale-se que no mês subsequente à última edição do Tais Timor, Timor-Leste - agora nação independente - teve, por um breve espaço de tempo, o seu primeiro jornal totalmente produzido e redigido em português, o Correio de Timor - facto que não ocorria desde 1975 com o desaparecimento de $A$ Voz de Timor. O Correio de Timor saiu às ruas no dia 13 de Junho de 2002 (tendo sido encerrado no primeiro semestre de 2003) em formato tablóide, com 12 páginas, numa tiragem de 2000 exemplares, com periodicidade quinzenal e distribuição gratuita. Embora propriedade de empresários portugueses do ramo de hotelaria e restauração (Eduardo Santos e João Noronha), o jornal era produzido por uma equipa de cinco pessoas sob a direcção do timorense Aleixo Corte Real, ex-diretor da Imprensa Nacional em Timor-Leste. Apesar das promessas de apoios oficiais, não houve concretizações, e o jornal dependia de escassa publicidade e dispunha de precária infra-estrutura: "o jornal [era] feito num computador antigo, com parte dos componentes cedidos por uma firma de informática local, numa sala de um hotel de Díli"11.

\section{Resumo}

Durante a Administração Transitória das Nações Unidas (1999 a 2002) em Timor-Leste, colocou-se em circulação um jornal publicado em quatro línguas: português, tétum, bahasa indonésia e inglês. Este estudo procura demonstrar, em títulos retirados da edição em língua portuguesa, a emergência de uma voz (ethos) que busca auxiliar na reconstrução identitária timorense.

\section{Abstract}

During the United Nations Transitory Administration in East Timor (1999 to 2002), there was a newspaper which was published in four languages: Portuguese, Tetun, Bahasa Indonesia and English. This article shows in some titles of the Portuguese edition the appearance of a new voice (ethos) which looks for helping the Timorese identity reconstruction.

${ }^{11}$ Conforme PNN - agencianoticias.com - http://www.jornalistas.com /noticia=58 [cap.em 11/06/2002]. 